\title{
People, trust and government: Getting the measure
}

Written by: Lara Fleischer, OECD Statistics Directorate
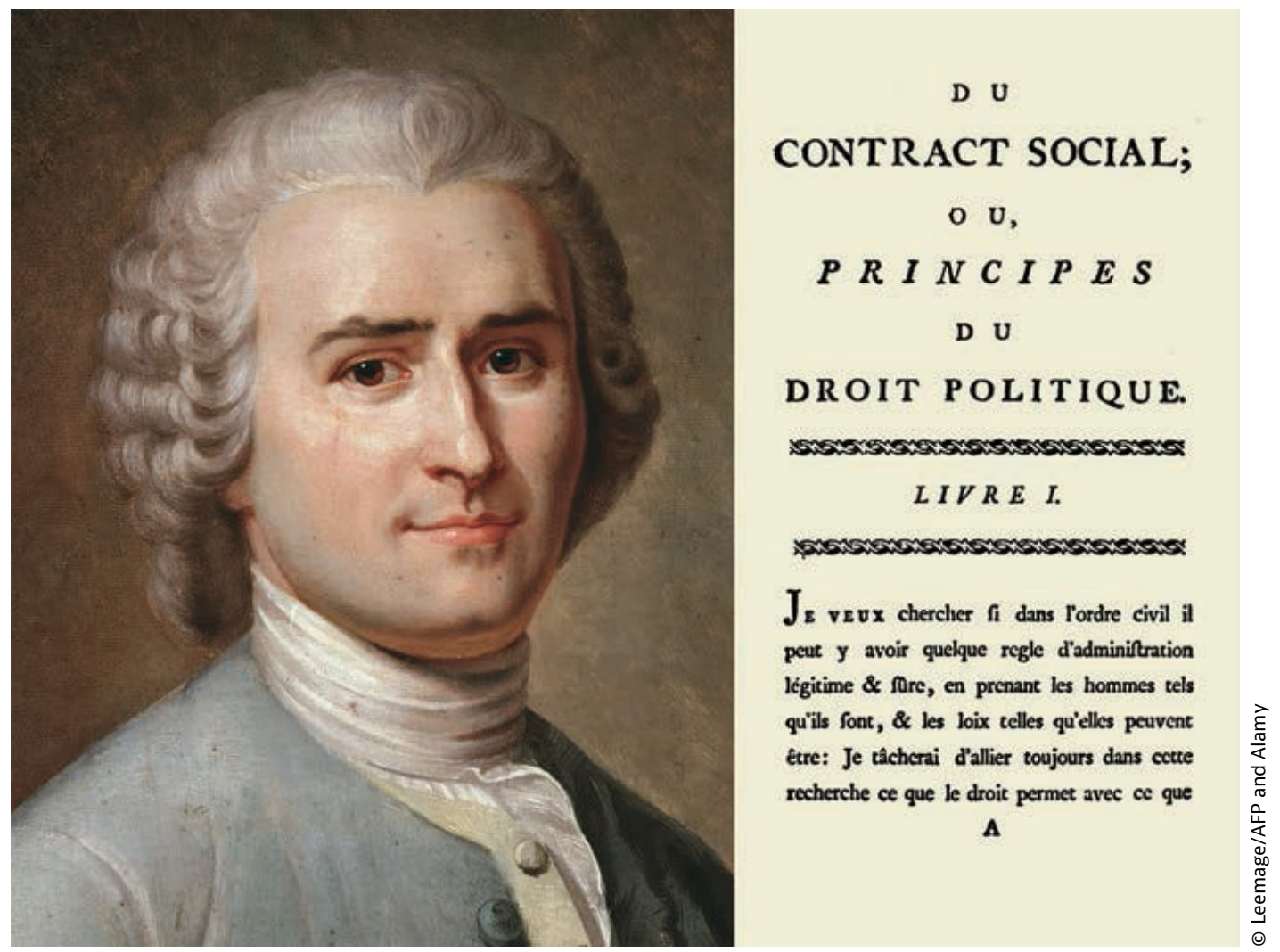

Jean-Jacques Rousseau and The Social Contract

Is trust between people and their governments crumbling? What the great philosopher Jean-Jacques Rousseau (our picture) called the social contract, whereby free citizens voluntarily agree to concede authority to the state in their own interest, could be in question. The OECD's How's Life? 2017 report finds that only 38\% of people in OECD countries say they trust their government. In 2006, this figure was around $42 \%$. Why is there such a "disconnect" between citizens and their elected representatives? 
The 2008 crisis is often blamed and could well be a factor. Indeed, trust has fallen by more than 15 percentage points in Greece, Portugal and Spain-some of the OECD countries hardest hit by the crisis. They have also seen the largest falls (or smallest growth) in household income and earnings since 2005, as well as some of the largest increases in long-term unemployment. By contrast, in Germany, Poland and the Slovak Republic, which are some of the countries where trust has increased the most, the average resident is generally better off than they were in 2005. Nevertheless, the trust issue goes beyond the Great Recession and there is more to it than simple economics. In the US, where opinion polls measuring confidence in federal government go back to the late 1950s, trust has been consistently falling over the long term.

There may be other sources for the disconnect between citizens and their government. How's Life? shows that the political class does not always reflect the people it serves. In the 11 OECD countries for which data is available, manual, agricultural and service workers make up $44 \%$ of the working population, but only $13 \%$ of legislators. Politicians are much more likely to have had a professional or senior management career. Not surprisingly, people might feel politicians are out of touch with their daily lives and unable to understand their basic struggles, from the cost of living to their need for quality public services.

Additionally, How's Life? finds that more than half of OECD residents consider corruption to be widespread in their government.

Average confidence in national government in the period 2014-16, and the change with respect to the period 2005-07

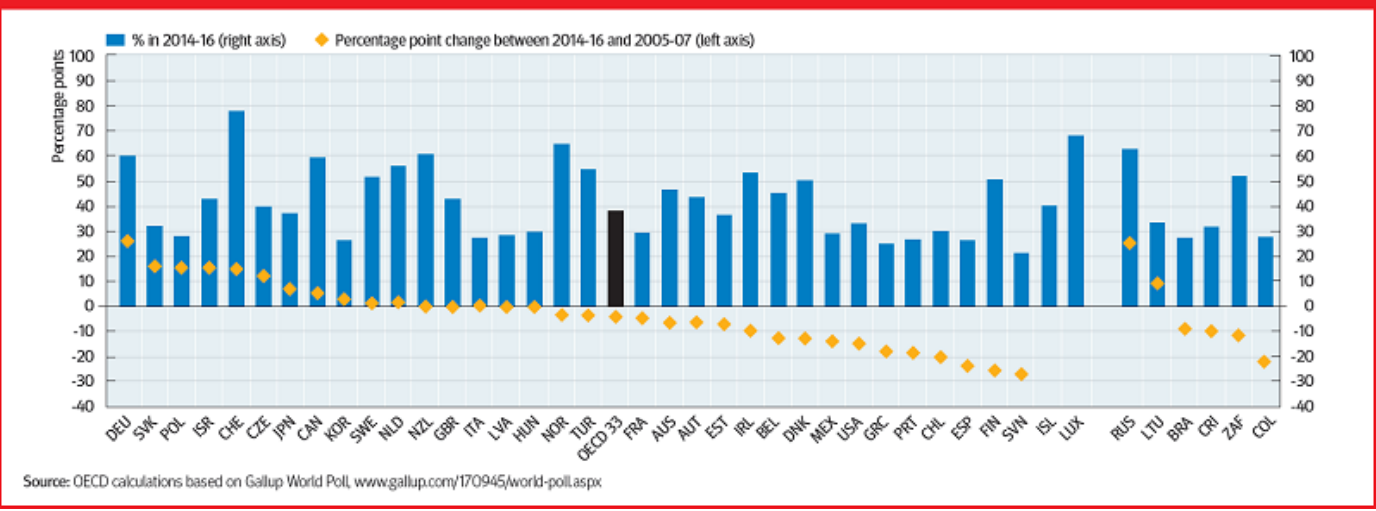

Deep and chronic distrust of government impedes the smooth and stable functioning of institutions. For one thing, this is bad for economic activities that require the confidence of investors and consumers.

But distrust is bad for democracy, too. The social contract is a two-sided coin. Good governance requires active citizen participation, but what we are seeing instead are people who are disengaging from traditional forms of politics. Voter turnout across the OECD has been steadily declining, and more so among people that are already the least well-represented in public life. How's Life? shows that younger people and those with lower incomes are less likely to go to the polls: 
self-reported voter turnout is 14 percentage points lower for people in the bottom income quintile compared to those in the top quintile, and turnout for people aged 65 or more is around 17 percentage points higher than among youth aged 18-24. The trouble is that this disaffection gives the elderly, the more educated and the wealthy a greater political say compared to the rest of the population. This has affected the way people vote as well: in Europe, distrust of institutions has gone hand-in-hand with a rise in voting for non-mainstream, populist parties.

That said, voting is the most traditional form of civic engagement, and new types of activism (think of hashtag campaigns, the Occupy or Black Lives Matter movements) have been emerging. However, there is little evidence on whether groups on the margins have shifted to these to make their voices heard. Tellingly, How's Life? notes that only one in three people in the OECD feels they have influence on what the government does. This feeling is even weaker among the less educated and less wealthy.

The first step in addressing the trust crisis is to monitor data regularly, analyse trends and identify what is needed to strengthen and restore trust. But, with the exception of Australia, Canada, and New Zealand, trust measurement does not have a long tradition in official statistics and is not collected frequently enough or in a way that is internationally comparable.

One reason trust has not been part of statistical offices' standard repertoire is its inherent intangibility. If you ask a person through a questionnaire whether they trust their government, is their answer good enough in terms of statistical quality?

The newly released OECD Guidelines on Measuring Trust offers international recommendations on collecting, publishing and analysing trust data to make it easier for national statistical offices to do so. (Besides trust in institutions, the guidelines also focus on trust in other people, which is a key element of social capital.) On the question of statistical quality, the guidelines provide evidence about the validity and reliability of trust data. It examines non-response rates, the relationship between self-reported trust measures and other proxies such as experimental behavioural indicators, and the consistency of results across surveys and over time. They conclude that we are indeed only at the beginning of fully understanding measures of trust in institutions, but that existing evidence of their statistical quality is encouraging. In order to answer remaining questions, more official data on trust and their potential determinants should be collected.

The guidelines feature five different question modules, with a core module that can readily be inserted into household surveys measuring trust in parliament, the police and the civil service. 
The guidelines are designed to build the evidence base needed to restore trust. Left unchecked, the growing alienation between people and institutions will feed the disengagement and frustration we are now witnessing in some countries.

What is your view? Do you trust your government? What do you suggest should be done to win the public's trust back?

Share this story at http://oe.cd/28N

\section{References}

Algan, Yann et al., (2017) “The European trust crisis and the rise of populism", Brookings Papers on Economic Activity, Washington, DC www.brookings.edu/ wp-content/uploads/2017/09/4_alganetal.pdf

OECD (2017), OECD Guidelines on Measuring Trust http://dx.doi.org/ 10.1787/9789264278219-en

People, trust and government: Getting the measure http://dx.doi.org/10.1787/ how_life-2017-en 